\title{
The Effects of Physical Activity on Self-Esteem: A Comparative Study
}

\author{
Seyed Reza Mousavi Gilani, ${ }^{1,}$ and Alireza Dashipour ${ }^{2}$ \\ ${ }^{1}$ Department of Physical Education, School of Medicine, Zahedan University of Medical Sciences, Zahedan, IR Iran \\ ${ }^{2}$ Department of Nutrition, School of Medicine, Zahedan University of Medical Sciences, Zahedan, IR Iran \\ "Corresponding author: Seyed Reza Mousavi Gilani, Department of Physical Education, School of Medicine, Zahedan University of Medical Sciences, Zahedan, IR Iran. Tel.: \\ +98-9119376971, Fax: +98-5413425728, E-mail: srmg45@yahoo.com
}

Received 2015 December 31; Revised 2016 February 12; Accepted 2016 February 21.

\begin{abstract}
Background: Exercise is a way to improve self-esteem.

Objectives: The purpose of this study was to investigate the effects of eight weeks of aerobic exercise on the self-esteem of medical students at Zahedan University of Medical Sciences in Iran.

Patients and Methods: This study used a 58-item Coopersmith inventory to measure the self-esteem of 84 male students who participated in an exercise program as an intervention. Both dependent and independent t-tests, as well as a chi square test, were applied using SPSS software.

Results: The results showed that although the self-esteem average score was not significant before the intervention, it increased significantly in the experimental group. In the experimental group, the variation in the meanself-esteem score was 32.36-42.89 before and after the intervention.

Conclusions: Our findings revealed that aerobic exercise increases self-esteem. An improvement in educational, family, social, and general self-esteem scores was seen only in the experimental group.
\end{abstract}

Keywords: Family, Physical Activity, Self Esteem

\section{Background}

Self-esteem, a term used in psychology to express the degree to which individuals feel positive about themselves (1), is an aspect of mental health, one of the most important issues currently affecting general public health and government policies (2). In particular, the prevention and treatment of psychological problems in children and in young people represent an issue that has recently received significant attention. There are many individual, social, and environmental factors that influence mental health, including the aspect of self-esteem (3).

The prevalence of psychological and behavioral problems in Iran is not clearly evident; however, some studies have found that they range from $7.3 \%$ to $39.8 \%$ (4). In some countries, approximately $10 \%-20 \%$ of children and adolescents have psychological and behavioral problems, $7 \%$ of which require psychological treatment (3). The most recent studies have found that in the United Kingdom, 1 in 4 people demonstrate at least one diagnosable mental health disorder during their lifetime $(5,6)$.

Today, the treatment of patients' physical health has received more attention by mental health services (7). An individual's physical activities have been shown to have strong positive effects on his or her mental health (8-10). Moreover, previous studies have shown that physical activities are beneficial in the management of psychologi- cal issues, such as anxiety, depression, anger, tension, reaction to stress, self-efficacy, and self-esteem $(11,12)$. Good self-esteem enhances mental growth and plays a prominent role in an individual's thoughts, feelings, values, and goals. People with higher levels of self-esteem evaluate themselves positively and have an appropriate, positive attitude toward themselves (13). Maslow argues that not only does a sense of self-respect provide us with a sense of inner security and self-confidence, it encourages us to assume that we are worthy and deserving. However, when we do not respect ourselves, we feel inferior, discouraged, and disabled when it comes to dealing with life (14).

Researchers have suggested several ways for improving self-esteem. One of them is physical activity, which helps us to acquire a higher degree of mental and physical power and prompts us to feel better about our quality of life. Studies have shown that because mobility and exercise improve an individual's adequacy and efficiency, physical activity and exercise have positive effects on selfesteem (15). In addition, there has been a long historical association between self-esteem and exercise behavior (16). Some studies have indicated that there is a positive correlation between physical activity and self-esteem in adults (17) and that exercise has a significant emotionally positive therapeutic effect on adolescent anxiety (18). Findlay et al. showed that elite, competitive athletes have a higher level of athletic competence, a more attractive physical appear- 
ance, and a greater degree of self-esteem than non-athletes (19). Pangrazi found that engaging in physical activity and sports can generate a feeling of success. Being successful in sports provides an immediate positive perception, which in turn can create competence and self-acceptance in athletes (20).

\section{Objectives}

The purpose of this study was to investigate the effects of eight weeks of aerobic exercise on the self-esteem of medical students at Zahedan University of Medical Sciences in Iran.

\section{Patients and Methods}

\subsection{Participants}

The present study was designed to perform clinical trials with the participation of male students. Eighty-four male students were randomly selected and randomly assigned to one of two groups: experimental group $(n=42)$ or a control group $(n=42)$.

\subsection{Measurement}

Participants completed a Self-Report Questionnaire that included the following demographic information: age, parents' occupations, parents' education level, birth order, sibling(s), family economic status, and average of the previous semester's score. The Coopersmith selfesteem inventory the school form (SEI) was used to measure self-esteem before and after intervention. The SEI consists of 58 items to which participants respond "Like me" or "Unlike me." Eight of the scale items assess lie score measurements (21). Total self-esteem (SE) is the recommended measure for overall SE. The measure has been found to have a high level of validity and reliability (ranging from 0.82 to 0.88 ); and Cronbach's alpha was reported at $0.77-0.88$ in a number of studies $(21,22)$. The scale range is $0-50$; a higher score denotes a higher SE level. Scores less than or equal to 26 are interpreted as weak SE, scores of 27 - 43 indicates a mid-level SE, and scores equal to or higher than 44 are considered to represent a high level of SE (13). The other items, which are divided into four categories of SE, are public, social, family, and educational, with $26,8,8$, and 8 items, respectively. A respondent's score of more than four out of eight lie detectors indicates that the test had low validity. A Persian-translated version of the Coopersmith 58-item test was used; studies conducted in Iran have shown this test to have acceptable validity and reliability (13).

\subsection{Procedure}

The experimental group did aerobic exercise under the researcher's observation for eight weeks, while the control group did not participate in extra activity during this period. The experimental group practiced three sessions a week, and each session comprised 45 minutes of exercise, including stretching, endurance running (aerobic), and cool-down movements. Aerobic exercise intensity was applied during each period to increase the heart rate to $60 \%$ - 70\% of the baseline. If participants were unable to take part in the aerobic exercise program or failed to attend it for three consecutive sessions (regardless of the reason, unexpected or otherwise), they were excluded. After eight weeks of regular aerobic exercises, the subjects' SE number was measured again, and the results were compared with those of the initial study. The participants' demographic data was used to assess the homogeneity of the two groups.

\subsection{Statistical Analyses}

Mean and standard deviations were calculated for the quantitative variables; frequency and percentage were used for the qualitative variables. Normal distribution was tested by using the Kolmogorov-Smirnov test. A dependent samples t-test was used to compare the mean of the SE scores before and after intervention in each group. Repeated measures ANOVA was used to compare the SE scores of the groups before and after intervention. The chi-square test was used to compare the groups' qualitative variables. $\mathrm{P}<0.05$ was considered the level of significance. The statistical analysis of the data was performed using SPSS statistical software version 16 (SPSS Inc., Chicago, IL).

\section{Results}

Four control-group participants were excluded from the study (because of incomplete questionnaire), and four experimental-group participants were excluded due to incorrect participation in the exercise sessions; the remaining participants, 38 men in each group, were assessed. The mean age was $22 \pm 1.44$ and $21 \pm 2.70$ years in the experimental and control groups, respectively. The occupation most associated with fathers was "employee" $34.20 \%$ of the experimental-group participants and $34.02 \%$ of the control-group participants). "Housekeeping" was the maternal occupation with the highest percentage in both experimental and control groups (52.6\% and $68.4 \%$, respectively). Moreover, the level of education most often associated with fathers in the experimental group was "bachelor's degree" (34.02\%), while "diploma” was most often mentioned in the control group (39.05\%). The level of education most often associated with mothers in both the 
experimental and control groups was "lower than diploma" (42.1\% and $47.4 \%$, respectively). The economic status noted in both experimental and control groups, based on self-statement, was normal (47.4\% and 63.2\%, respectively). There were no significant differences between groups in age $(P=1)$, father's occupation ( $P=0.70)$, mother's occupation $(\mathrm{P}=0.23)$, father's or mother's level of education $(\mathrm{P}=$ 0.11 and $\mathrm{P}=0.66$, respectively), economic status $(\mathrm{P}=0.29)$, birth order, $(\mathrm{P}=0.1)$ and sibling $(\mathrm{s})(\mathrm{P}=0.48)$. The average of the previous semester's score was $(16.21 \pm 1.25)$ in the experimental group and (15.48 \pm 1.55$)$ in the control group. There was a statistically significant difference between the two groups $(\mathrm{P}=0.03)$. The participants' demographic characteristics are detailed in Table 1.

At the beginning of the study, 6 (15.8\%) and 4 (10.5\%) of participants in experimental and control groups, respectively, demonstrated weak SE; 32 (84.2\%) and (89.5\%) of participants in experimental and control groups, respectively, demonstrated mid-level SE; no high levels of SE were demonstrated in either group. At the end of the study, however, no weak levels of SE were found; 20 (52.6\%) and (38\%) of the experimental-and control-group participants, respectively, demonstrated mid-level SE;18 (47.4\%) and zero (0\%) of participants in experimental and control groups respectively, demonstrated high levels of SE. The chi-square test showed no significant difference between groups at the beginning of the study ( $\mathrm{P}=0.49$ ); however, the difference observed at the end of the study was significant $(\mathrm{P}<$ 0.0001).

The repeated measures ANOVA showed statistically significant differences between control and experimental groups in overall SE and in the scores of SE dimensions. Although an independent t-test showed no significant differences between groups in overall SE and in the scores of SE dimensions before intervention, significant differences were found after intervention. The dependent t-test showed statistically significant differences in the experimental group after the intervention in terms of increases in overall SE scores as well as in family, social, educational, and general scores $(\mathrm{P}<0.0001)$. In the control group, only the general SE score was significantly increased at the end of the study $(\mathrm{P}=0.03$; please see Table 2$)$.

\section{Discussion}

The purpose of this study was to investigate the effects of eight weeks of aerobic exercise on the self-esteem of male students. The results showed that the mean SE scores increased significantly in participants who received the intervention. Participating in regular aerobic exercise for eight weeks as an intervention appeared to increase the mean SE score. This result can be interpreted to mean that there is a relationship between exercise and increased SE. The results of this study correspond with those of other studies (3,13, 23-25). Ghaffari et al. conducted a study with students in an experimental group before and after regular aerobic exercise and found that the mean SE score increased significantly, from $93.1 \pm 8.2$ to $111.4 \pm 8.1(\mathrm{P}<$ 0.0001). In the control group, it was $91.2 \pm 7.9$ before the intervention, and at the end of the study it was $92.4 \pm 6.3$ (not significant) (13). Ferdowsi et al. reported a significant difference in terms of self-esteem and mental health between the experimental group and the control group after 12 weeks of aerobic exercises (23). A study by Ekeland et al. also resulted in a positive response among participants (3). In a study by Biddle and Asar, no significant differences in the subjects' self-esteem resulted from physical activity before or after the intervention in the control group (26). A study by Schneider et al. showed that intervention (four sessions of physical activity per week) had positive effects on self-esteem in depressed patients (24). In the present study, the variation in the SE score in the experimental group was 10.5, while in the control group it was 2.4. In a study by Bobbio, differences in SE scores emerged in the group that participated in physical activity (27). A study by Bowker showed the relationship between sports participation and self-esteem during early adolescence. The results supported a mediation model, with physical selfesteem mediating the relationship between sports participation and general self-esteem (28). After conducting survey research, Raustorp found that the self-esteem of 42 women affected by breast cancer improved after they participated in aerobic exercises (29). Additionally, Bicer (30), in a study entitled the effects of 12 weeks of aerobic exercise on students' self-esteem, found that the average SE score of the subjects before the intervention was 33.21 and after the intervention, the mean SE increased to 36.32. The author concluded that aerobic exercise increased the SE score (31). A study by Dishman conducted to examine the effects of physical activity and sports participation on depression symptoms among adolescent girls showed that there was a strong positive relation between overall physical self-concept and self-esteem and a moderate inverse between self-esteem and depression symptoms (32).

Likewise, the results of the present study showed that there was a significant difference in the educational selfesteem of the students in the experimental group (Table 2). Hisken found a positive relationship between self-esteem and academic achievement (33), while Hall observed a significant relationship between self-esteem and educational performance and attainment (34). Similarly, the results of research conducted by Lambourne et al. showed that physical activity has a direct impact on the subjects' aerobic fitness and and indirect impact on their academic 
Table 1. Comparison of the Subjects' Demographic Variables Based on Group

\begin{tabular}{|c|c|c|c|c|c|c|}
\hline & & Experimental & Control & Total & PValue & \\
\hline \multirow{6}{*}{ Father's occupation } & Employee & $13(34.2)$ & $13(34.2)$ & $26(34.2)$ & 0.70 & \\
\hline & Worker & $7(18.4)$ & $11(28.9)$ & $18(23.7)$ & & \\
\hline & Retired & $7(18.4)$ & $5(13.2)$ & $12(15.8)$ & & \\
\hline & Business Person & $11(28.9)$ & $9(23.7)$ & $20(26.3)$ & & \\
\hline & Total & $38(100)$ & $38(100)$ & $76(100)$ & & \\
\hline & Employee & $7(18.4)$ & $7(18.4)$ & $14(18.4)$ & 0.23 & \\
\hline \multirow{4}{*}{ Mother's occupation } & Retired & $4(10.5)$ & $4(10.5)$ & $8(10.5)$ & & \\
\hline & Business Person & $7(18.4)$ & $1(10.6)$ & $8(10.5)$ & & \\
\hline & Housekeeping & $20(52.6)$ & $26(60.5)$ & $46(60.5)$ & & \\
\hline & Total & $38(100)$ & $38(100)$ & $76(100)$ & & \\
\hline \multirow{6}{*}{$\begin{array}{l}\text { Father's level of } \\
\text { education }\end{array}$} & High School or Lower & $12(31.6)$ & $11(28.9)$ & $23(30.3)$ & 0.11 & \\
\hline & Diploma & $6(15.8)$ & $15(39.5)$ & $21(27.6)$ & & \\
\hline & Associate's Degree & $7(18.4)$ & $5(13.2)$ & $12(15.8)$ & & \\
\hline & $\begin{array}{c}\text { Bachelor's Degree or } \\
\text { Higher }\end{array}$ & $13(34.2)$ & $7(18.4)$ & $20(26.3)$ & & \\
\hline & Total & $38(100)$ & $38(100)$ & $76(100)$ & & \\
\hline & High School or Lower & $16(42.1)$ & $18(47.4)$ & $34(44.7)$ & 0.66 & \\
\hline \multirow{3}{*}{$\begin{array}{l}\text { Mother's level of } \\
\text { education }\end{array}$} & Diploma & $14(36.8)$ & $16(42.1)$ & $30(39.5)$ & & \\
\hline & Associate's Degree & $4(10.5)$ & $2(5.3)$ & $6(7.9)$ & & \\
\hline & $\begin{array}{c}\text { Bachelor's Degree or } \\
\text { Higher }\end{array}$ & $4(10.5)$ & $2(5.3)$ & $6(7.9)$ & & \\
\hline \multirow{6}{*}{$\begin{array}{l}\text { Family's economic } \\
\text { status }\end{array}$} & Total & $38(100)$ & $38(100)$ & $76(100)$ & & \\
\hline & Poor & $5(13.2)$ & $2(5.3)$ & $7(9.2)$ & 0.29 & \\
\hline & Normal & $18(47.4)$ & $24(63.2)$ & $42(55.3)$ & & \\
\hline & Good & $15(39.5)$ & $12(31.6)$ & $27(35.5)$ & & \\
\hline & Total & $38(100)$ & $38(100)$ & $76(100)$ & & \\
\hline & & Mean \pm SD & $\mathbf{n}$ & $\mathbf{t}$ & df & P Value \\
\hline \multirow{2}{*}{ Age } & Experimental & $20.9 \pm 2.4$ & 38 & \multirow{2}{*}{0.0} & \multirow{2}{*}{74} & \multirow{2}{*}{1.0} \\
\hline & Control & $20.9 \pm 2.7$ & 38 & & & \\
\hline \multirow[t]{2}{*}{ Birth order } & Experimental & $2.1 \pm 1.1$ & 38 & \multirow{2}{*}{-1.9} & \multirow{2}{*}{74} & \multirow{2}{*}{0.06} \\
\hline & Control & $2.7 \pm 1.6$ & 38 & & & \\
\hline \multirow[t]{2}{*}{ Sibling(s) } & Experimental & $3.5 \pm 1.6$ & 38 & \multirow{2}{*}{-1.0} & \multirow{2}{*}{74} & \multirow{2}{*}{0.29} \\
\hline & Control & $4.0 \pm 2.0$ & 38 & & & \\
\hline \multirow{2}{*}{$\begin{array}{l}\text { Previous semester's } \\
\text { score }\end{array}$} & Experimental & $16.2 \pm 1.2$ & 38 & \multirow{2}{*}{2.2} & \multirow{2}{*}{74} & \multirow{2}{*}{0.02} \\
\hline & Control & $15.41 \pm 1.5$ & 38 & & & \\
\hline
\end{tabular}

achievement (35). In this study, after intervention, there was a significant difference (increase) in the experimental group's family SE score when compared to that of the control group (Table 2).

Based on the results of this study, a significant difference was between the social SE of the experimental group compared to the control group (Table 1). The Bicer's study showed no significant differences between the social development of male and female students due to aerobic exercises (30). The results of a study by Majlesi et al. indicated that aerobic exercise is effective in increasing the students' level of social development (36). In general, a per- 
Table 2. Comparison of the Subjects' Mean SE Scores and Their Dimensions Before and After Intervention

\begin{tabular}{|c|c|c|c|c|c|c|c|c|}
\hline Category & Group & Stage of Study & Mean \pm SD & $\mathbf{N}$ & $\mathbf{t}$ & df & PValue & Effect Size \\
\hline \multirow{4}{*}{$\begin{array}{l}\text { Overall } \\
\text { self-esteem }\end{array}$} & \multirow{2}{*}{ Experimental } & before & $32.3 \pm 5.8$ & 38 & \multirow{2}{*}{-10.9} & \multirow{2}{*}{37} & \multirow{2}{*}{$<0.0001$} & \multirow{2}{*}{-2.3} \\
\hline & & after & $42.8 \pm 2.1$ & 38 & & & & \\
\hline & \multirow{2}{*}{ Control } & before & $33.5 \pm 5.3$ & 38 & \multirow{2}{*}{-1.7} & \multirow{2}{*}{37} & \multirow{2}{*}{0.09} & \multirow{2}{*}{-} \\
\hline & & after & $35 \pm 4.6$ & 38 & & & & \\
\hline \multirow{4}{*}{$\begin{array}{l}\text { Educational } \\
\text { self-esteem }\end{array}$} & \multirow{2}{*}{ Experimental } & before & $4.9 \pm 1.6$ & 38 & \multirow{2}{*}{-2.3} & \multirow{2}{*}{37} & \multirow{2}{*}{$<0.0001$} & \multirow{2}{*}{-1.2} \\
\hline & & after & $6.6 \pm 1.0$ & 38 & & & & \\
\hline & \multirow{2}{*}{ Control } & before & $4.8 \pm 1.4$ & 38 & \multirow{2}{*}{-0.9} & \multirow{2}{*}{37} & \multirow{2}{*}{0.36} & \multirow{2}{*}{-} \\
\hline & & after & $5.0 \pm 1.4$ & 38 & & & & \\
\hline \multirow{4}{*}{$\begin{array}{l}\text { Family } \\
\text { self-esteem }\end{array}$} & \multirow[t]{2}{*}{ Experimental } & before & $5.2 \pm 2.3$ & 38 & \multirow[t]{2}{*}{-4.2} & \multirow[t]{2}{*}{37} & \multirow[t]{2}{*}{$<0.0001$} & \multirow[t]{2}{*}{-1} \\
\hline & & after & $7.0 \pm 0.9$ & 38 & & & & \\
\hline & \multirow{2}{*}{ Control } & before & $4.9 \pm 1.5$ & 38 & \multirow{2}{*}{-1.4} & \multirow{2}{*}{37} & \multirow{2}{*}{0.17} & \multirow{2}{*}{-} \\
\hline & & after & $5.3 \pm 1.4$ & 38 & & & & \\
\hline \multirow{4}{*}{$\begin{array}{l}\text { Social } \\
\text { self-esteem }\end{array}$} & Experimental & before & $4.5 \pm 1.5$ & 38 & -4.3 & 37 & $<0.0001$ & -1.1 \\
\hline & & after & $5.9 \pm 1.2$ & 38 & & & & \\
\hline & Control & before & $4.4 \pm 1.2$ & 38 & -0.7 & 37 & 0.49 & - \\
\hline & & after & $4.6 \pm 1.5$ & 38 & & & & \\
\hline & Experimental & before & $17.2 \pm 3.4$ & 38 & -8.8 & 37 & $<0.0001$ & -2.2 \\
\hline General & & after & $22.7 \pm 1.5$ & 38 & & & & \\
\hline self-esteem & Control & before & $18.9 \pm 3.9$ & 38 & -2.2 & 37 & 0.03 & -0.3 \\
\hline & & after & $20.1 \pm 3.0$ & 38 & & & & \\
\hline
\end{tabular}

son's prosperity and success depends on his or her feeling of self-worth and self-respect. Having a good sense of one's own self is one of the basic needs of human life. Individuals need to regard themselves as being physically, intellectually, and emotionally well and worthy. Such emotion serves to motivate an individual to succeed in fulfilling life's tasks, including the physical exercise to which self-esteem is closely linked and which is being addressed by major education organizations.

In both groups, at the end stage of the study, general SE had significantly increased. The effect size of the experimental group was -2.2 (indicating a large effect); the effect size of the control group was - 0.3 (indicating a low effect), thus magnifying the differences in the experimental group, which were higher than those of the control group.

\subsection{Conclusions}

As today's youths face many psychological, social, and emotional problems, coaches are given opportunities to help them cope with their evolving lives. Young people need to feel good and to be good, which will help them achieve a safe and healthy lifestyle. The lack of a high level of self-esteem may cause adolescents and young adults to deviate from their life paths (23). A review of the literature combined with our findings reveals that regular exercise and physical activity, as well as the use of exercise therapy, are effective in increasing self-esteem and mental balance. Therefore, exercise can be used effectively to create positive attitudes toward ourselves and our cognitive abilities. In general, university officials, who have access to information about different aspects of students' personalities, should provide conditions that nurture their students' self-esteem and which encourage them to participate in sports activities and exercise programs as an effective strategy for ensuring their mental health, and ultimately, their personal growth.

\subsection{Limitations}

The limitation of this study was the necessity for females to conduct the sport training of females and for males to conduct the sport training of males; male students were therefore chosen to receive training by male trainers. Performing this study with female or mixedgender groups would be beneficial. 


\section{Acknowledgments}

The authors are grateful to the Zahedan University of Medical Science and to the medical science students who participated in this study.

\section{References}

1. Sonstroem RJ. 6 Physical Self-Concept: Assessment and External Validity. Exerc Sport Sci Rev. 1998;26(1):133-64.

2. Vergnano S, Menson E, Smith Z, Kennea N, Embleton N, Clarke P, et al. Characteristics of Invasive Staphylococcus aureus in United Kingdom Neonatal Units. Pediatr Infect Dis J. 2011;30(10):850-4. doi: 10.1097/INF.0b013e318224546d. [PubMed: 21654546].

3. Ekeland E, Heian F, Hagen KB. Can exercise improve self esteem in children and young people? A systematic review of randomised controlled trials. Br J Sports Med. 2005;39(11):792-8. doi: 10.1136/bjsm.2004.017707. [PubMed:16244186] discussion 792-8.

4. Mohammadi MR, Yazdi Bagheri S, Rahgozar M, Mesgarpour B, Alhavaegi Bab A, Lotfi A, et al. An epidemiological study of psychiatric disorders in Hamadan province, 2001. Sci J Hamedan Univ Med Sci. 2004;11(3):28-36.

5. HMSO . Making it happen A guide to delivering mental health promotion. ; 2001.

6. The office of national Statistics . Cenus 2001 2001. Available from: www.ons.gov.uk.

7. Commission S. The abandoned illness: a report from the Schizophrenia Commission. London: Rethink Mental Illness; 2012

8. Blair SN, Kohl HW, Gordon NF, Paffenbarger RJ. How much physical activity is good for health?.Annu Rev Public Health. 1992;13:99-126. doi: 10.1146/annurev.pu.13.050192.000531. [PubMed: 1599603].

9. Pate RR, Pratt M, Blair SN, Haskell WL, Macera CA, Bouchard C, et al. Physical activity and public health. A recommendation from the Centers for Disease Control and Prevention and the American College of Sports Medicine. JAMA. 1995;273(5):402-7. [PubMed: 7823386].

10. Erikssen G, Liestol K, Bjornholt J, Thaulow E, Sandvik L, Erikssen J. Changes in physical fitness and changes in mortality. Lancet. 1998;352(9130):759-62. doi: 10.1016/S0140-6736(98)02268-5. [PubMed: 9737279].

11. Goodwin RD. Association between physical activity and mental disorders among adults in the United States. Prev Med. 2003;36(6):698-703. [PubMed: 12744913].

12. Hansen CJ, Stevens LC, Coast JR. Exercise duration and mood state: how much is enough to feel better?. Health Psychol. 2001;20(4):26775. [PubMed: 11515738].

13. Ghafari FFZ, Mazloom SR. The Effects of Groups Regular Training on Self-esteem in nurse student. Med Sci Babol Univ J. 2007;9(1):52-7.

14. Maslow AH. Self Actualization and Beyoud in GFT challenges of $\mathrm{Hu}-$ manistic psychology. New York: Mc Graw press; 2000.

15. Sepah Mansour M, Memar E, Azmoudeh M. The relationship between self-esteem and self-efficacy with persuasion in educational managers. Soc Cogn. 2013;1(2):92-100.

16. Dembeck K. Physical Activity and Self-Esteem in Females During Late Adolescence. ; 2011.

17. Opdenacker J, Delecluse C, Boen F. The longitudinal effects of a lifestyle physical activity intervention and a structured exercise intervention on physical self-perceptions and self-esteem in older adults. J Sport Exerc Psychol. 2009;31(6):743-60. [PubMed: 20384010].
18. Horn TS, Claytor RP, Seraganian P. Developmental aspects of exercise psychology. Exercise psychology: The influence of physical exercise on psychological processes. ; 1993.

19. Findlay LC, Bowker A. The link between competitive sport participation and self-concept in early adolescence: a consideration of gender and sport orientation. J Youth Adolesc. 2009;38(1):29-40. doi: 10.1007/s10964-007-9244-9. [PubMed: 19636789].

20. Pangrazi R. Physical education, self-concept, and achievement. J Phys Educ Recreat Dance. 1982;53(9):16-8.

21. Herz L, Gullone E. The relationship between self-esteem and parenting style a cross-cultural comparison of Australian and Vietnamese Australian adolescents. J Cross Cultur Psychol. 1999;30(6):742-61.

22. Mecca AM, Smelser NJ, Vasconcellos J. The social importance of self esteem. Univ of California Press; 1989.

23. Ferdowsi M, Marashian F, Marashian S. The Effects of 12-Week Aerobic Exercises on Rate of Mental Health in Male Students of Ahvaz Payam Noor University. Human Mov. 2010;11(2):167-71.

24. Schneider M, Dunton GF, Cooper DM. Physical Activity and Physical Self-Concept among Sedentary Adolescent Females; An Intervention Study. Psychol Sport Exerc. 2008;9(1):1-14. doi: 10.1016/j.psychsport.2007.01.003. [PubMed: 18443656].

25. Moore JB, Mitchell NG, Bibeau WS, Bartholomew JB. Effects of a 12week resistance exercise program on physical self-perceptions in college students. Res Q Exerc Sport. 2011;82(2):291-301. doi: 10.1080/02701367.2011.10599757. [PubMed: 21699109].

26. Biddle SJ, Asare M. Physical activity and mental health in children and adolescents: a review of reviews. Br J Sports Med. 2011;45(11):886-95. doi: 10.1136/bjsports-2011-090185. [PubMed: 21807669].

27. Bobbio A. Relation of physical activity and self-esteem. Percept Mot Skills. 2009;108(2):549-57. doi: 10.2466/PMS.108.2.549-557. [PubMed 19544960].

28. Bowker A. The relationship between sports participation and selfesteem during early adolescence. Can J Behav Sci. 2006;38(3):214.

29. Raustorp A. Eight years secular trends of physical self-esteem among Swedish adolescents. Int J Adolesc Med Health. 2010;22(2):237-47. [PubMed: 21061924].

30. Bicer SY. The effect 12 weeks of aerobic training on social maturity development, selfesteem and body image among school students. Int J Sport Stud. 2013;3(1):59-66.

31. Josephs RA, Markus HR, Tafarodi RW. Gender and self-esteem.JPers Soc Psychol. 1992;63(3):391-402. [PubMed: 1403622].

32. Dishman RK, Hales DP, Pfeiffer KA, Felton GA, Saunders R, Ward DS, et al. Physical self-concept and self-esteem mediate cross-sectional relations of physical activity and sport participation with depression symptoms among adolescent girls. Health Psychol. 2006;25(3):396407. doi: 10.1037/0278-6133.25.3.396. [PubMed: 16719612].

33. Hisken LJ. The correlation between self-esteem and student reading ability, reading level, and academic achievement. University of Central Missouri; 2011

34. Hall AL. The relationship between academic achievement, academic performance and self-esteem of high school juniors at a public high school in central Florida. ProQuest; 2007.

35. Lambourne K, Hansen DM, Szabo AN, Lee J, Herrmann SD, Donnelly JE. Indirect and direct relations between aerobic fitness, physical activity, and academic achievement in elementary school students. Ment Health Phys Act. 2013;6(3):165-71. doi:10.1016/j.mhpa.2013.06.002. [PubMed: 25984236].

36. Majlesi M, Shabanibahar G, Azadian E, Hamedan I. A study of the ef fects of an aerobic training program on the social maturity of male non-athlete students: the case of an Iranian experience. J Am Sci. ;7(8):742-7. 